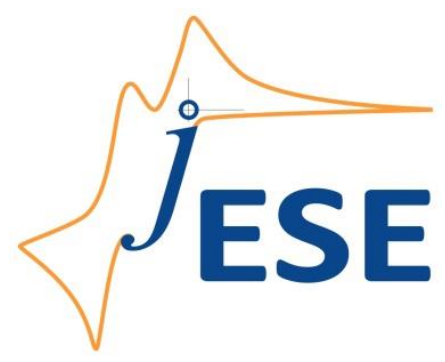

Open Access : : ISSN 1847-9286

www.jESE-online.org

Original scientific paper

\title{
Influence of various metallic oxides on the kinetic of the oxygen evolution reaction on platinum electrodes
}

\author{
Kambire Ollo, Pohan Lemeyonouin Aliou Guillaume, Appia Foffié Thiéry Auguste, \\ Gnamba Corneil Quand-Meme, Kondro Konan Honoré, Ouattara Lassiné ${ }^{\bowtie}$ \\ Laboratoire de Chimie Physique, UFR SSMT, Université Félix Houphouët-Boigny de Cocody, Abidjan, \\ 22 BP 582 Abidjan 22, Côte d'Ivoire
}

Corresponding Author: ouatlassine@yahoo.fr ; Tel: +22502143382

Received: December 23, 2014; Revised: April 13, 2015; Published: August 26, 2015

\begin{abstract}
$\mathrm{Pt},{ }_{50} \mathrm{Pt}-{ }_{50} \mathrm{RuO}_{2}$ and ${ }_{50} \mathrm{Pt}-{ }_{50} \mathrm{IrO}_{2}$ electrodes were prepared on titanium (Ti) substrate by thermal decomposition techniques. The micrographs of ${ }_{50} \mathrm{Pt}-{ }_{50} \mathrm{RuO}_{2}$ and ${ }_{50} \mathrm{Pt}-{ }_{50} \mathrm{IrO}_{2}$ have revealed that their surfaces are rough with cracked structures in contrast to platinum which exhibits smooth, compact and homogeneous surface. The richer the electrode surface in platinum, thinner is the crack size and also more compact is the electrode surface. The electrodes have also been characterized electrochemically by cyclic voltammetry in acidic $\left(\mathrm{HClO}_{4}\right)$ and alkaline $(\mathrm{KOH})$ electrolytes. These characterizations showed that the surface of the ${ }_{50} \mathrm{Pt}-{ }_{50} \mathrm{RuO}_{2}$ and ${ }_{50} \mathrm{Pt}-{ }_{50} \mathrm{IrO}_{2}$ electrodes were composed of platinum and metal dioxide active sites. The Tafel slope obtained on Pt, ${ }_{50} \mathrm{Pt}-{ }_{50} \mathrm{RuO}_{2}$ and ${ }_{50} \mathrm{Pt}-{ }_{50} \mathrm{IrO}_{2}$ for the oxygen evolution reaction (OER) were respectively 120, 90 and $44 \mathrm{mV} \mathrm{dec}^{-1}$ in acid electrolyte. In the alkaline electrolyte, they were 119, 87 and $42 \mathrm{mV} \mathrm{dec}^{-1}$ on $\mathrm{Pt},{ }_{50} \mathrm{Pt}-{ }_{50} \mathrm{RuO}_{2}$ and ${ }_{50} \mathrm{Pt}-{ }_{50} \mathrm{IrO}_{2}$ electrodes, respectively, indicating that for the prepared electrodes, Tafel slopes are the same in acidic and in alkaline media. Moreover, in acidic and in alkaline media, the kinetic of the oxygen evolution reaction was faster on ${ }_{50} \mathrm{Pt}-{ }_{50} \mathrm{RuO}_{2}$ and ${ }_{50} \mathrm{Pt}-{ }_{50} \mathrm{IrO}_{2}$ than Pt owing to a synergetic effect of Pt and the oxides. That additional effect of the surface component ${ }_{50} \mathrm{Pt}-{ }_{50} \mathrm{RuO}_{2}$ and ${ }_{50} \mathrm{Pt}-{ }_{50} \mathrm{IrO}_{2}$ electrodes let them possess higher electrocatalytic activity towards OER than Pt in the two media. Though the kinetic of the oxygen evolution reaction is practically the same in acidic and alkaline media for all the electrodes, OER occurred at lower overpotential in alkaline electrolyte than in acidic electrolyte on the prepared electrodes.
\end{abstract}

\section{Keywords}

Platinum, Ruthenium dioxide, Iridium dioxide, Tafel slope, Cyclic voltammetry, Electrocatalytic activity, Oxygen evolution reaction 


\section{Introduction}

Oxygen evolution reaction (OER) has been extensively studied in electrochemistry because of its importance in many fields such as fuel cells, wastewater treatment, chlorine evolution, corrosion, water electrolysis [1-7]. OER reaction kinetics and mechanism aspects drew a great attention and still continue to be investigated. Because of the use of electrochemistry to solve environment pollution problems [8-10], a particular interest was directed towards the search of better electrocatalysts that could lead to a decrease of the OER overpotential. In the above mentioned field, platinum played an important role because of its good electronic and corrosion resistance properties. Although platinum is known to be one of the best electrocatalyst in acidic electrolytes, its high cost requires its replacement with new materials. Used for the oxidation of organics such as methanol and ethanol, platinum undergoes electrode fouling consequently reducing its electrooxidation activities. Since it is known that OER depends mainly on chemical and structural properties of electrode materials surface, our interest was focused on platinum and transition metal oxide modified platinum electrodes. Indeed, since the discovery of Dimensionnally stable anodes (DSAs) by Beer around 1970, a lot of research efforts were made on such kind of electrodes in relation to a variety of processes has been carried out including OER. It has been shown that among the DSAs, iridium dioxide and ruthenium dioxide exhibit good OER performance. In prior investigation in our team, it has been shown that combining $50 \%$ molar ratio of Pt and metallic oxides led to higher activity for organic oxidations [11]. The aim of the present study was to investigate the electrocatalytic activity and the kinetics of the OER on the same kind of electrode i.e. platinum modified with various transition metal oxides.

\section{Experimental}

The electrodes used in the following work were all prepared in our laboratory with appropriate metallic precursors. The coating precursors were prepared from $\mathrm{H}_{2} \mathrm{PtCl}_{6}, 6 \mathrm{H}_{2} \mathrm{O}$ (Fluka), $\mathrm{RuCl}_{3}, \times \mathrm{H}_{2} \mathrm{O}$ (Fluka) and $\mathrm{H}_{2} \mathrm{IrCl}_{6}, 6 \mathrm{H}_{2} \mathrm{O}$ (Fluka). All the precursors were dissolved in pure isopropanol (Fluka) used as solvent. The commercial products were used as received without any further treatment.

The titanium substrates on which the electrode films were deposited have the following dimension $1.6 \times 1.6 \times 0.5 \mathrm{~cm}$. The surface of each substrate was sandblasted to ensure good adhesion of the deposit on it. After, sandblasting, all the substrates were washed vigourously in water and then in isopropanol to clean their surface from residual sands. The substrates were then dried in an oven at $80{ }^{\circ} \mathrm{C}$ and weighed. After that, the precursor was applied by a painting procedure on the titanium (Ti) substrate then put in an oven for $15 \mathrm{~min}$ at $80^{\circ} \mathrm{C}$ in air to allow the solvent evaporation. Then after, it is put in a furnace at $400{ }^{\circ} \mathrm{C}$ for $15 \mathrm{~min}$ in air to allow the decomposition of the precursor. Theses steps were repeated until the desired mass of the coating is reached. A final decomposition of $1 \mathrm{~h}$ was done at $400{ }^{\circ} \mathrm{C}$. The electrodes prepared by this technique are platinum (Pt), platinum-iridium dioxide $\left.{ }_{50} \mathrm{Pt}-{ }_{50} \mid \mathrm{IO}_{2}\right)$ and platinum-ruthenium dioxide $\left({ }_{50} \mathrm{Pt}_{-50} \mathrm{RuO}_{2}\right)$ electrodes. For the combined electrodes, a mixture of $50 \%$ molar ratio of the corresponding precursor was used. The deposit loading was about $5 \mathrm{~g} \mathrm{~m}^{-2}$ on each titanium substrate.

The physical characterization of the electrodes were performed using a scanning electronic microscopy (SEM, ZEISS, SUPRA 40VP) device.

The voltammetric measurements were performed under either $1 \mathrm{mV} \mathrm{s}^{-1}$ or $100 \mathrm{mV} \mathrm{s}$ on the prepared electrodes in a three-electrode electrochemical cell using an Autolab PGStat 20 (Ecochemie). The counter electrode (CE) was a platinum wire and the reference electrode (RE) was 
a saturated calomel electrode (SCE). All the potential were reported against SHE according to the following relation: $E / V$ vs. $S H E=E / V$ vs. SCE +0.25 . To decrease the contribution of ohmic losses, the reference electrode was mounted in a luggin capillary and placed close to the working electrode by a distance of $1 \mathrm{~mm}$. In fact, ohmic drop is known to increase the value of the Tafel slope and careful attention was to be paid on it during experiment. In order to reduce totally the residual ohmic drop, the polarization curve should be corrected according to method described elsewhere [12-15]. A brief description of the correction is given as followed.

The overpotential $\eta / \mathrm{V}$ observed in the experiment can be given by

$$
\eta / \mathrm{V}=a+b \ln j+j R
$$

where $a / \mathrm{V}$ is the Tafel constant, $b / \mathrm{V} \mathrm{dec}{ }^{-1}$ is the Tafel slope, $j / \mathrm{A} \mathrm{cm}^{-2}$ is the current density and $R / \Omega \mathrm{cm}^{-2}$ is the total area-specific uncompensated resistance of the system, which is assumed to be constant. The derivative of equation (1) with respect to current density gives equation (2) from which $b$ and $R$ can be easily obtained by plotting $d \eta / d j$ as a function of $1 / j$

$$
\frac{\mathrm{d} \eta}{\mathrm{d} j}=\frac{b}{j}+R
$$

The estimation of $\mathrm{R}$ allows correcting the experimental overpotential by substracting the ohmic drop $j R$ according to equation (3)

$$
\eta_{\text {corr }}=\eta-j R
$$

where $\eta_{\text {corr }}$ stands for the corrected overpotential

During the calculations, the derivatives $d \eta / d j$ was replaced by their finite elements $\Delta \eta / \Delta j$ estimated from each pair of consecutive experimental points.

The apparent exposed area of the working electrode was $1 \mathrm{~cm}^{2}$.

For the electrochemical investigations $\mathrm{HClO}_{4}$ (Fluka), $\mathrm{KOH}$ (Fluka) were used as received for the preparation of the solutions employed in that work with distilled water. All the experiments were made at ambient temperature of $25^{\circ} \mathrm{C}$.

\section{Results and discussion}

\section{Physical characterization of the prepared electrodes}

In Figure 1, the micrographs of the prepared electrodes were presented. It appears that the surface was totally covered by the deposit. The surface of the platinum electrode seems to be smooth, compact and almost homogeneous (Figure 1a). The surface of ${ }_{50} \mathrm{Pt}_{-50} \mathrm{RuO}_{2}$ (Figure $1 \mathrm{~b}$ ) is rough and seems to be compact as that of platinum but cracks were observed like those of DSA's $[16,17]$. Such finding indicated that the electrode surface of the ${ }_{50} \mathrm{Pt}-{ }_{50} \mathrm{RuO}_{2}$ electrode is composed by platinum and ruthenium dioxide. In Figure $1 \mathrm{c}$, the prepared ${ }_{50} \mathrm{Pt}-{ }_{50} \mathrm{IrO}{ }_{2}$ electrode is shown and its surface presents almost the same characteristic as ${ }_{50} \mathrm{Pt}-{ }_{50} \mathrm{RuO}_{2}$ but in this case, the electrode surface is highly rough with more cracks. The size of the cracks are thinner as generally observed at such magnification for pure DSAs possibly due to the presence of platinum which contributes to render the combined electrode surface to have compact structures. 
a

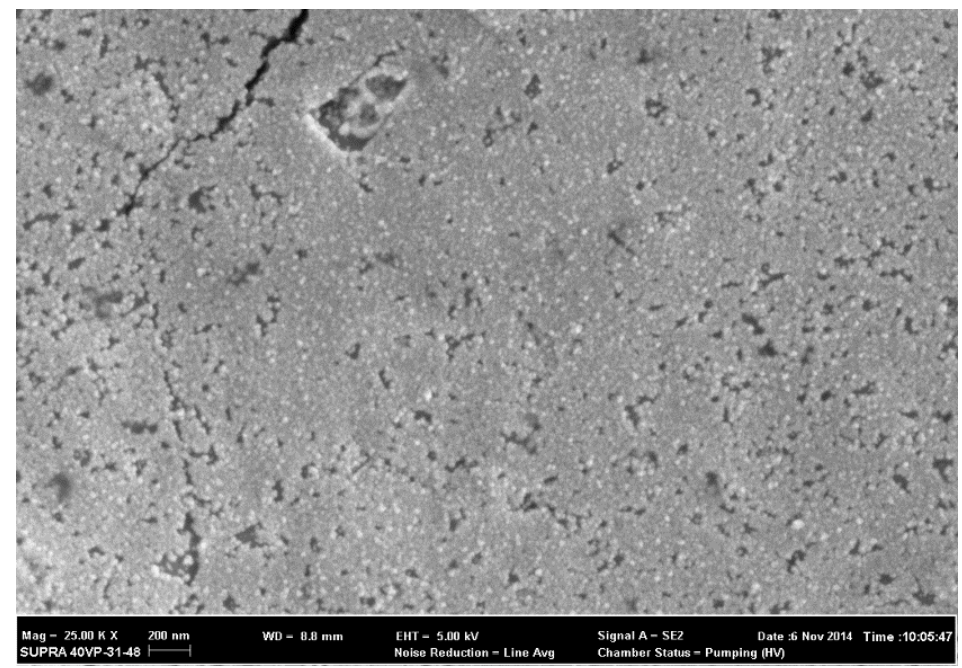

b

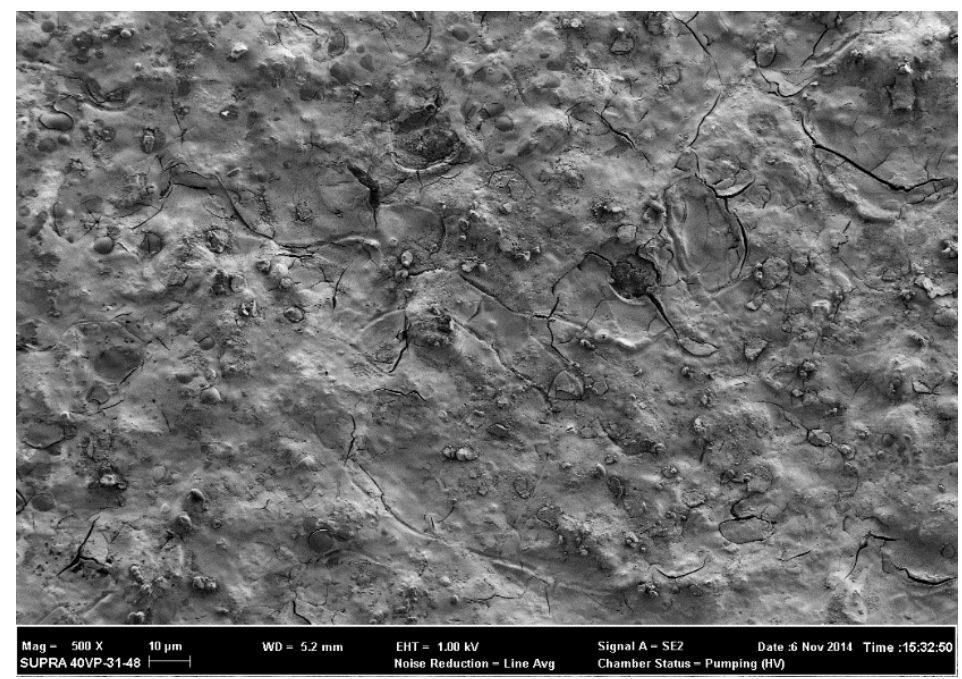

c

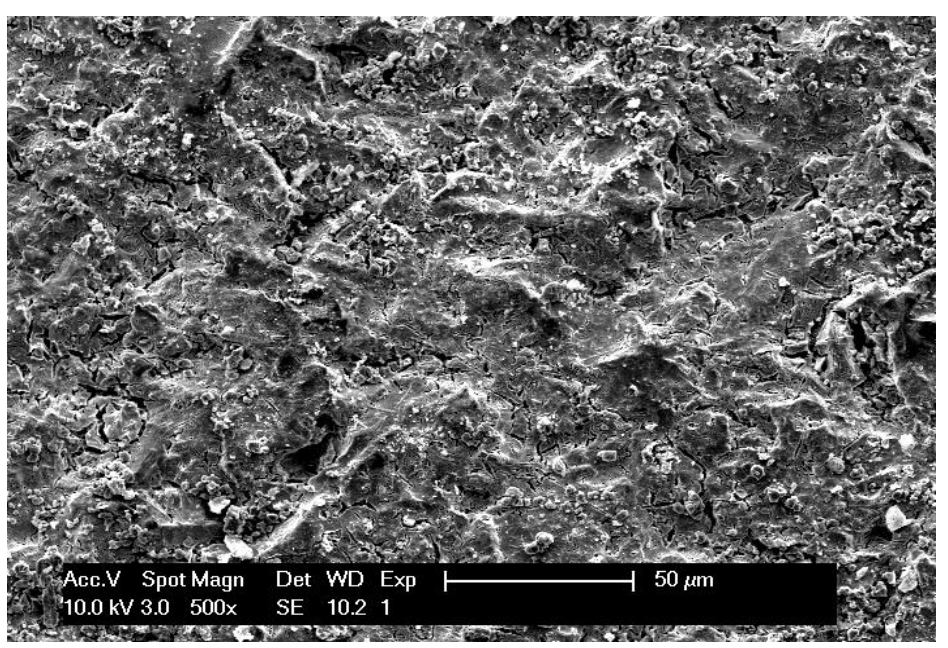

Figure 1: Scanning electron micrographs of Pt(a), ${ }_{50} \mathrm{Pt}-{ }_{50} \mathrm{RuO}_{2}(\boldsymbol{b})$ and ${ }_{50} \mathrm{Pt}-{ }_{50} \mathrm{IrO} \mathrm{O}_{2}(\boldsymbol{c})$

\section{Electrochemical characterization of the electrodes in perchloric acid medium}

Cyclic voltammetric measurements were performed on a platinum electrode in perchloric acid $1 \mathrm{M}$ under a scan rate of $100 \mathrm{mV} \mathrm{s}^{-1}$ and the results were depicted in Figure 2a. The figure showed the usual feature generally observed with polycrystalline platinum in acidic media [18]. Well defined adsorption and desorption peaks located in the potential domain between 0 and $0.4 \mathrm{~V}$ 
were shown. The double layer region characterized by an almost zero current in the forward potential scan followed by oxide formation domain $(0.74 \mathrm{~V}-1.51 \mathrm{~V})$ and an oxide reduction peak at $0.72 \mathrm{~V}$ (backward potential scan) were also presented. A rapid increase in the current related to OER started at $1.51 \mathrm{~V}$.

In Figures $2 \mathrm{~b}$ and $2 \mathrm{c}$, the voltammograms resulted from the investigation made on the platinum modified electrodes were presented. For such investigation, ${ }_{50} \mathrm{Pt}-{ }_{50} \mathrm{IrO}_{2}$ and ${ }_{50} \mathrm{Pt}-{ }_{50} \mathrm{RuO}_{2}$ have been used. As a general response, the modified electrodes led to voltammograms resembling to that obtained with pure platinum electrode. That result indicated that the surface of the modified electrodes is partly composed of platinum clusters. The voltammetric charges of the combined electrodes are higher than that of platinum. That is due to the presence of metal oxides on the electrode surface. The voltammogram of the ${ }_{50} \mathrm{Pt}-{ }_{50} \mathrm{RuO}_{2}$ electrode presents a feature that bears more resemblance to that of platinum than the voltammogram of ${ }_{50} \mathrm{Pt}_{-50} \mathrm{IrO}_{2}$ compared to that of platinum. That result indicated that $\mathrm{RuO}_{2}$ has more electronic and structure affinity with platinum than $\mathrm{IrO}_{2}$ towards platinum. It can also be deduced from those results that ${ }_{50} \mathrm{Pt}-{ }_{50} \mathrm{RuO}_{2}$ surface is composed of much platinum clusters due to its migration from the inside of the coating to its surface during the thermal decomposition of the precursor. But in case of ${ }_{50} \mathrm{Pt}_{-50} \mathrm{IrO}_{2}$, a hindering effect of $\mathrm{IrO}_{2}$ on platinum migration occurs that results in lower spread of platinum on such composite electrode surface. Although this observation is made, presence of metal oxide and platinum on the electrode surface showed synergetic effect i.e. increasing in active sites than platinum used alone. In the high potential domain, using oxygen evolution as a probe reaction to investigate the electrocatalytic activity of the prepared electrodes, it appeared that the onset of the potential at the increase in current are $1.43 \mathrm{~V} ; 1.41 \mathrm{~V}$ and $1.51 \mathrm{~V}$ on ${ }_{50} \mathrm{Pt}-{ }_{50} \mathrm{RuO}_{2},{ }_{50} \mathrm{Pt}-{ }_{50} \mathrm{IrO}{ }_{2}$ and $\mathrm{Pt}$ respectively. From these results, it appears that ${ }_{50} \mathrm{Pt}-{ }_{50} \mathrm{IrO}_{2}$ and ${ }_{50} \mathrm{Pt}-{ }_{50} \mathrm{RuO}_{2}$ are more electrocatalytic for OER than pure platinum owing to their low overpotential for OER than pure platinum electrode. For the prepared composite electrodes ${ }_{50} \mathrm{Pt}-{ }_{50} \mathrm{IrO}_{2}$ appeared to be more catalytic for OER than ${ }_{50} \mathrm{Pt}-{ }_{50} \mathrm{RuO}_{2}$. Such result is in accordance with the above obtained result and is explained by the fact that the surface of ${ }_{50} \mathrm{Pt}-{ }_{50} \mathrm{RuO}_{2}$ is mostly composed by platinum than on ${ }_{50} \mathrm{Pt}-{ }_{50} \mathrm{IrO}_{2}$ electrode. Indeed, mixing metallic oxides such as transition metal oxide led to an increase in the electrocatalytic behavior of platinum and/or the prepared electrode towards oxygen evolution reaction.

Plotting log $j$ versus the potential $E$, straight lines were obtained in the Tafel region as shown in Figure 3. The obtained Tafel slopes are presented in Table 1.

It is worth noting that Tafel slopes are an indicator of electrocatalytic activity. In fact, the lower the Tafel slope the faster the kinetics of the reaction and the more active the electrocatalyst is. From Table 1, it could be noticed that pure platinum exhibits a Tafel slope of $120 \mathrm{mV} \mathrm{dec} \mathrm{Ch}^{-1}$ wich is higher than those obtained on the composite electrodes. The Tafel slope of ${ }_{50} \mathrm{Pt}_{-}{ }_{50} \mathrm{RuO}_{2}$ is higher than that of ${ }_{50} \mathrm{Pt}-{ }_{50} \mathrm{IO}_{2}$. The exchange current densities have been determined (Table 1) and the obtained values indicated that the system $\mathrm{O}_{2} / \mathrm{H}_{2} \mathrm{O}$ is kinetically slow on all the investigated electrodes. Meanwhile, from these findings, regarding the Tafel slopes, it appears that OER is more rapid on ${ }_{50} \mathrm{Pt}_{-50} \mathrm{IrO}_{2}$ than on ${ }_{50} \mathrm{Pt}-{ }_{50} \mathrm{RuO}_{2}$ and sluggish on pure platinum electrode. These results are in accordance with the above obtained results where the onset of the potential of OER was concerned. In fact, as the surface of the electrode is dominated by platinum clusters in the following order ${ }_{50} \mathrm{Pt}-{ }_{50} \mathrm{IrO}_{2}<{ }_{50} \mathrm{Pt}-{ }_{50} \mathrm{RuO}_{2}<\mathrm{Pt}$ as shown by voltammetric investigation in acidic medium, an increase in the Tafel slope is observed. 

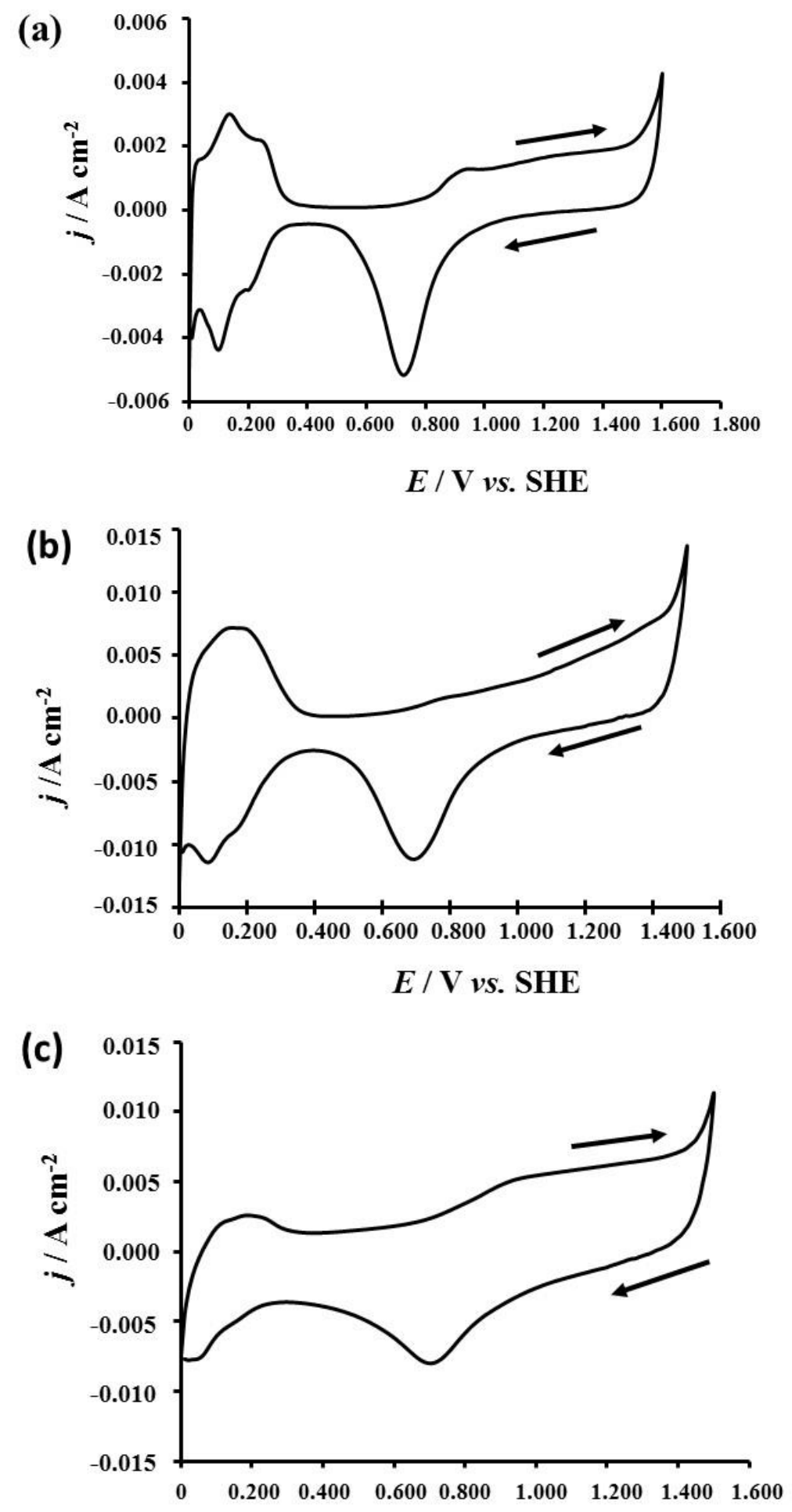

\section{E / V vs. SHE}

Figure 2: Cyclic voltammograms of Pt (a), ${ }_{50} \mathrm{Pt}_{-50} \mathrm{RuO}_{2}(\boldsymbol{b})$ and ${ }_{50} \mathrm{Pt}-{ }_{50} \mathrm{IrO} \mathrm{O}_{2}(\boldsymbol{c})$ in $1 \mathrm{M} \mathrm{HClO}_{4}$ at $100 \mathrm{mV} \mathrm{s}^{-1}, \mathrm{CE}$ : platinum, $\mathrm{T}=25^{\circ} \mathrm{C}$

Table 1: Tafel slopes and exchange current densities of various electrodes in $1 \mathrm{M} \mathrm{HClO}_{4}$; $\mathrm{v}=1 \mathrm{mV} \mathrm{s}^{-1} ; \mathrm{CE}$ : platinum; $\mathrm{T}=25^{\circ} \mathrm{C}$

\begin{tabular}{ccc}
\hline Electrodes & Tafel slope $/ \mathrm{mV} \mathrm{dec}^{-1}$ & Exchange current density $\boldsymbol{j}_{\mathbf{0}} \mathbf{1 0}^{\mathbf{4}} / \mathbf{A ~ c m}^{-2}$ \\
\hline $\mathrm{Pt}$ & 120 & 0.728 \\
${ }_{50} \mathrm{Pt}_{-50} \mathrm{RuO}_{2}$ & 90 & 4.375 \\
${ }_{50} \mathrm{Pt}_{50} \mathrm{IrO}_{2}$ & 44 & 1.069 \\
\hline
\end{tabular}



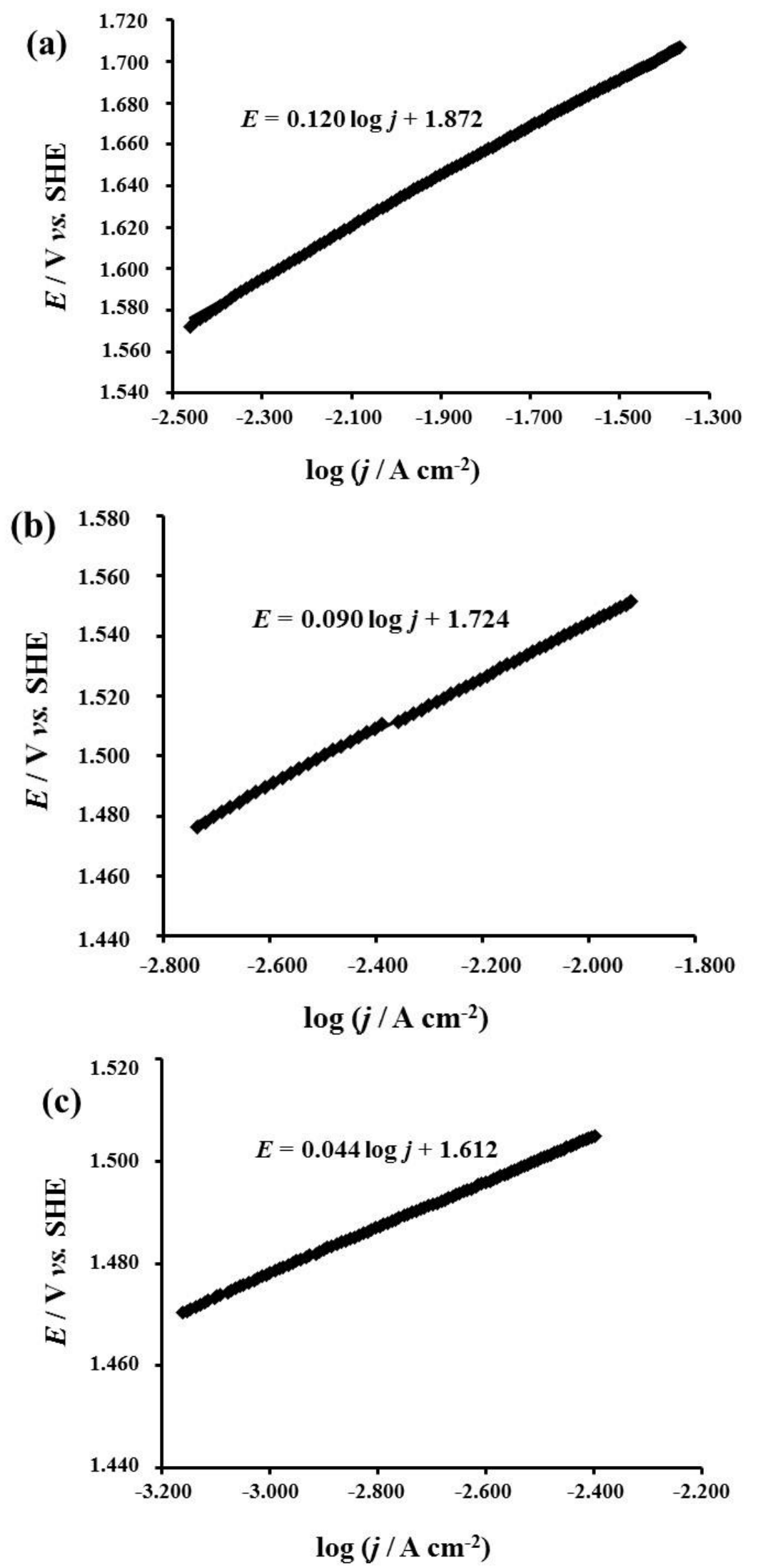

Figure 3 : Tafel line of Pt (a), ${ }_{50} P t-{ }_{50} \mathrm{RuO}_{2}(\boldsymbol{b})$ and ${ }_{50} \mathrm{Pt}-{ }_{50} \mathrm{IrO}_{2}(\boldsymbol{c})$ in perchloric acid $1 \mathrm{M}$; $\mathrm{v}=1 \mathrm{mV} \mathrm{s}^{-1} ; \mathrm{CE}:$ platinum; $\mathrm{T}=25^{\circ} \mathrm{C}$

Although the Tafel slopes delineate the rapidity of the kinetics occurring on the electrode surface, it is also related to the rate determining step in the OER mechanism. The electrodes 
presented thus different rate determining steps. From the literature, a globally accepted OER mechanism is described as followed in acidic media $[14,19]$.

$$
\begin{aligned}
& \mathrm{S}+\mathrm{H}_{2} \mathrm{O} \rightarrow \mathrm{S}-\mathrm{OH}+\mathrm{H}^{+}+\mathrm{e}^{-} \\
& \mathrm{S}-\mathrm{OH} \rightarrow \mathrm{SO}+\mathrm{H}^{+}+\mathrm{e}^{-} \\
& 2 \mathrm{SO} \rightarrow 2 \mathrm{~S}+\mathrm{O}_{2}
\end{aligned}
$$

where $\mathrm{S}$ stands for electrode active sites; $\mathrm{OH}$ and $\mathrm{O}$ represent adsorbed intermediates.

If the step (4) is the rate determining step, current density associated with reaction (4) can be given as:

$$
j_{1}=k F\left[\mathrm{H}_{2} \mathrm{O}\right] \Gamma\left(1-\theta_{1}-\theta_{2}\right) \exp \left[\frac{\alpha F}{R T} \eta\right]
$$

$j$ - current density, $k$ - constant of the kinetic of the reaction, $\Gamma$ - total active sites, $\theta_{1}$ and $\theta_{2}$ : rate of adsorbed $\mathrm{OH}$ and $\mathrm{O}$ respectively, $\alpha$ - charge transfer coefficient, $\eta$ - overpotential

Taking into account a second electron transfer taking place in step (5), the total faradic current density can be obtained through the following equation:

$$
j=2 j_{1}=2 k F\left[\mathrm{H}_{2} \mathrm{O}\right] \Gamma\left(1-\theta_{1}-\theta_{2}\right) \exp \left[\frac{\alpha F}{R T} \eta\right]
$$

Considering $K$ as

$$
K=2 k F\left[\mathrm{H}_{2} \mathrm{O}\right] \Gamma\left(1-\theta_{1}-\theta_{2}\right)
$$

(8) becomes

$$
\exp \left[\frac{\alpha F}{R T} \eta\right]=\frac{j}{K}
$$

Then

$$
\eta=\frac{R T \ln 10}{\alpha F} \log j-\frac{R T \ln 10}{\alpha F} \log K
$$

The expression of the Tafel slope is obtained by doing

$$
b_{\mathrm{a}}=\left(\frac{\partial \eta}{\partial \log |j|}\right)_{\mathrm{P}, \mathrm{T}, \mathrm{C}_{\mathrm{R}}}=\frac{R T \ln 10}{\alpha F}
$$

In the experimental condition $b_{\mathrm{a}}=120 \mathrm{mV} \mathrm{dec}{ }^{-1}$.

When each of the steps (5) and (6) is considered as a rate determining step, the corresponding Tafel slope would be $40 \mathrm{mV} \mathrm{dec}^{-1}$ and $15 \mathrm{mV} \mathrm{dec}^{-1}$ respectively.

According to these results and regarding the Tafel slopes of Table 1, one can consider that the rate determining step occurring on the platinum electrode is related to the hydroxyl radical adsorption on the active sites of that electrode (step 4) since the Tafel slope is $120 \mathrm{mV} \mathrm{dec}{ }^{-1}$. Such a result has been found by many other authors on platinum in acidic media $[20,21]$. With ${ }_{50} \mathrm{Pt}-$ ${ }_{50} \mathrm{IrO}_{2}$, a Tafel slope of $44 \mathrm{mV} \mathrm{dec}{ }^{-1}$ was found. That result indicated that the rate determining step is given by equation (5) of the proposed mechanism. With ${ }_{50} \mathrm{Pt}_{-50} \mathrm{RuO}_{2}$, the obtained Tafel slope is $90 \mathrm{mV} \mathrm{dec}{ }^{-1}$ which is almost close to $120 \mathrm{mV} \mathrm{dec}^{-1}$. Rate determining step is similar to that 
obtained with pure platinum but the kinetic of the OER is higher on that electrode than platinum owing to either a mixed kinetic control proceeding via unstable adsorption species such as $\mathrm{S}-\mathrm{OH}^{*}$ (Equations 13 and 14) [14,19] or the synergetic effect of the two surface components (Pt and $\left.\mathrm{RuO}_{2}\right)$.

$$
\begin{aligned}
& \mathrm{S}+\mathrm{H}_{2} \mathrm{O} \rightarrow \mathrm{S}-\mathrm{OH}^{*}+\mathrm{H}^{+}+\mathrm{e}^{-} \\
& \mathrm{S}-\mathrm{OH}^{*} \rightarrow \mathrm{S}-\mathrm{OH}
\end{aligned}
$$

Electrochemical characterization of the prepared electrodes in alkaline electrolyte

In the $0.5 \mathrm{M}$ potassium hydroxide electrolyte, voltammograms have been recorded on platinum electrode. The obtained result is depicted in Figure 4a. The trend of the curve is different to that of platinum in acidic medium. The voltammogram presents a rectangular shape in the potential window explored.

Figures $4 \mathrm{~b}$ and $4 \mathrm{c}$ show the voltammograms recorded on ${ }_{50} \mathrm{Pt}-{ }_{50} \mathrm{IrO}_{2}$ and ${ }_{50} \mathrm{Pt}-{ }_{50} \mathrm{RuO}_{2}$ electrodes. All the voltammograms showed almost the same feature. In the low potential domain, one observed superimposed voltammograms of platinum and ${ }_{50} \mathrm{Pt}-{ }_{50} \mathrm{RuO}_{2}$ indicating that the surface of ${ }_{50} \mathrm{Pt}-{ }_{50} \mathrm{RuO}_{2}$ electrodes is rich in platinum clusters. The onset of the oxygen evolution reaction potential decreased highly as platinum is associated with transition metal oxides $\left(\mathrm{IrO}_{2}\right.$ and $\left.\mathrm{RuO}_{2}\right)$. The obtained potential values are $0.67 \mathrm{~V}, 0.67 \mathrm{~V}$ and $0.78 \mathrm{~V}$ for ${ }_{50} \mathrm{Pt}_{-50} \mathrm{IrO}_{2},{ }_{50} \mathrm{Pt}_{-50} \mathrm{RuO}_{2}$ and Pt respectively. It appears that adding transition metal oxide such as ruthenium dioxide and iridium dioxide to platinum leads to electrodes with a higher electrocatalytic activity towards oxygen evolution reaction than pure platinum electrodes. That finding is in accordance with the results that are obtained in acidic medium indicating that the enhancement of the electrocatalytic activity of the composite electrodes could be due to a synergetic effect of the two elements that exist on the electrode surface.

Stability in the voltammograms was observed in that medium. That is the sign that no other oxide growth of the electrodes surface happened. In both media, platinum modified with $\mathrm{IrO}_{2}$ or $\mathrm{RuO}_{2}$ possesses the best electrocatalytic activity for OER than pure platinum.

The Tafel slopes of the electrodes used in this study have been determined in alkaline medium. The ohmic drop correction has been carried out like in acidic medium. Figure 5 shows the measured Tafel line of the electrodes. The obtained Tafel slopes are consigned in Table 2.

It appears that the slope decreases in the following order $\mathrm{Pt}>\mathrm{Pt}-\mathrm{RuO}_{2}>\mathrm{Pt}-\mathrm{IrO}_{2}$ indicating that the rate determining steps are not the same on all the electrodes. Regarding the Tafel slopes, ${ }_{50} \mathrm{Pt}$ ${ }_{50} \mathrm{IrO}_{2}$ seemed to behave as the best electrocatalyst for oxygen evolution reaction. In contrast, $\mathrm{Pt}$ presents the lowest electrocatalytic activity towards oxygen evolution reaction. Coupling platinum and iridium or ruthenium oxides helps to increase oxygen evolution kinetics. The exchange current densities have been determined (Table 2 ) and the obtained values indicated that the system $\mathrm{O}_{2} / \mathrm{OH}^{-}$is kinetically low on all the investigated electrodes. It worth indicating that the same Tafel slope was obtained on the prepared electrodes independently of the nature of the electrolyte.

Table 2. Tafel slopes of the prepared electrodes in $\mathrm{KOH} 0.5 \mathrm{M} ; \mathrm{v}=1 \mathrm{mV} \mathrm{s} \mathrm{s}^{-1} \mathrm{CE}:$ platinum ; RE :SHE; $T=25^{\circ} \mathrm{C}$

\begin{tabular}{ccc}
\hline Electrodes & Tafel slope, $\mathrm{V} \mathrm{dec}^{-1}$ & Exchange current density $\mathrm{j}_{\mathbf{0}} \mathbf{1 0}^{\mathbf{4}} / \mathrm{A} \mathrm{cm}^{-2}$ \\
\hline $\mathrm{Pt}$ & 119 & 0.186 \\
${ }_{50} \mathrm{Pt}-{ }_{50} \mathrm{RuO}_{2}$ & 87 & 0.140 \\
${ }_{50} \mathrm{Pt}-{ }_{50} \mathrm{IrO}_{2}$ & 42 & 10.83 \\
\hline
\end{tabular}


(a)

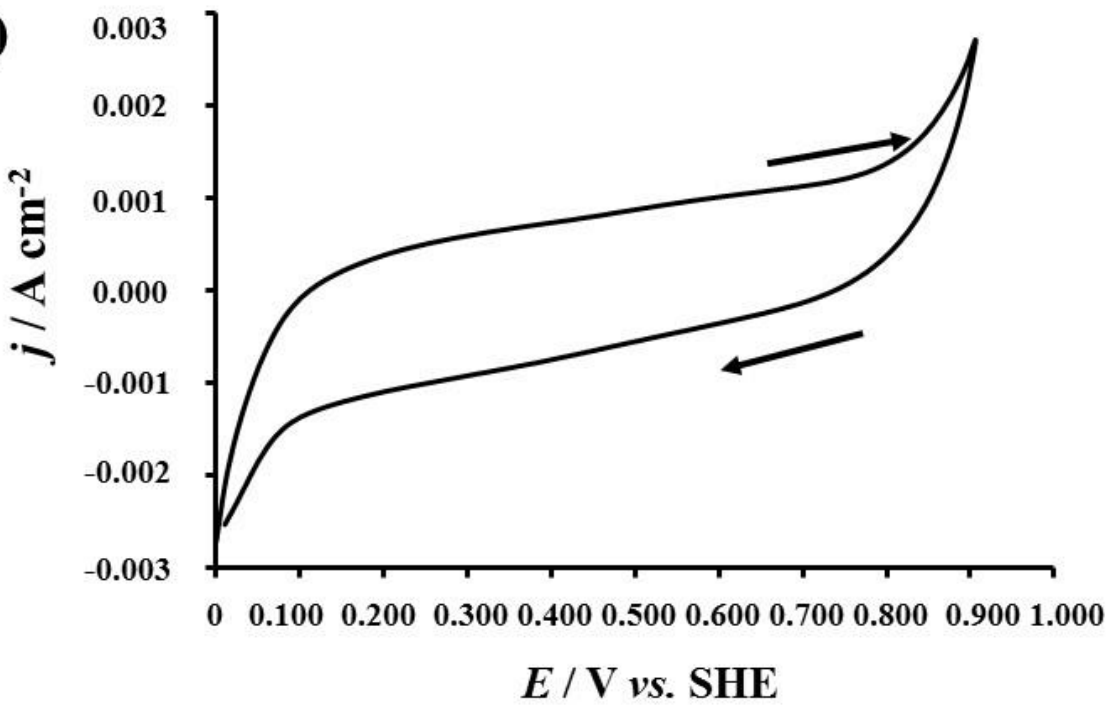

(b)
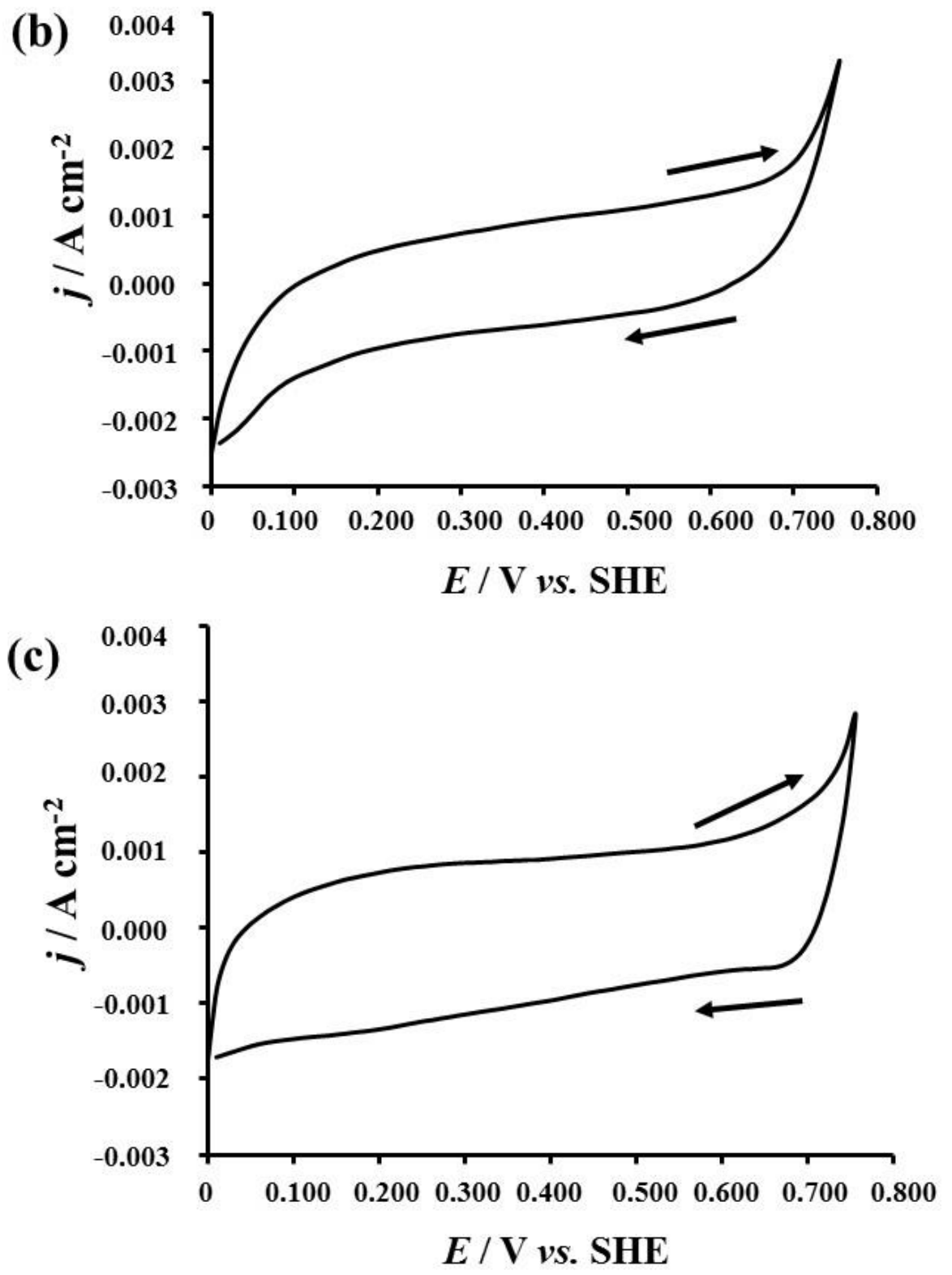

Figure 4. Cyclic voltammograms of Pt (a), ${ }_{50} \mathrm{Pt}_{50} \mathrm{RuO}_{2}$ (b) and ${ }_{50} \mathrm{Pt}^{-50 \mathrm{OlO}} \mathrm{O}_{2}$ (c) in $\mathrm{KOH} 0.5 \mathrm{M}$ at $100 \mathrm{mV} \mathrm{s}^{-1}, \mathrm{CE}$ : platinum, $\mathrm{T}=25^{\circ} \mathrm{C}$ 

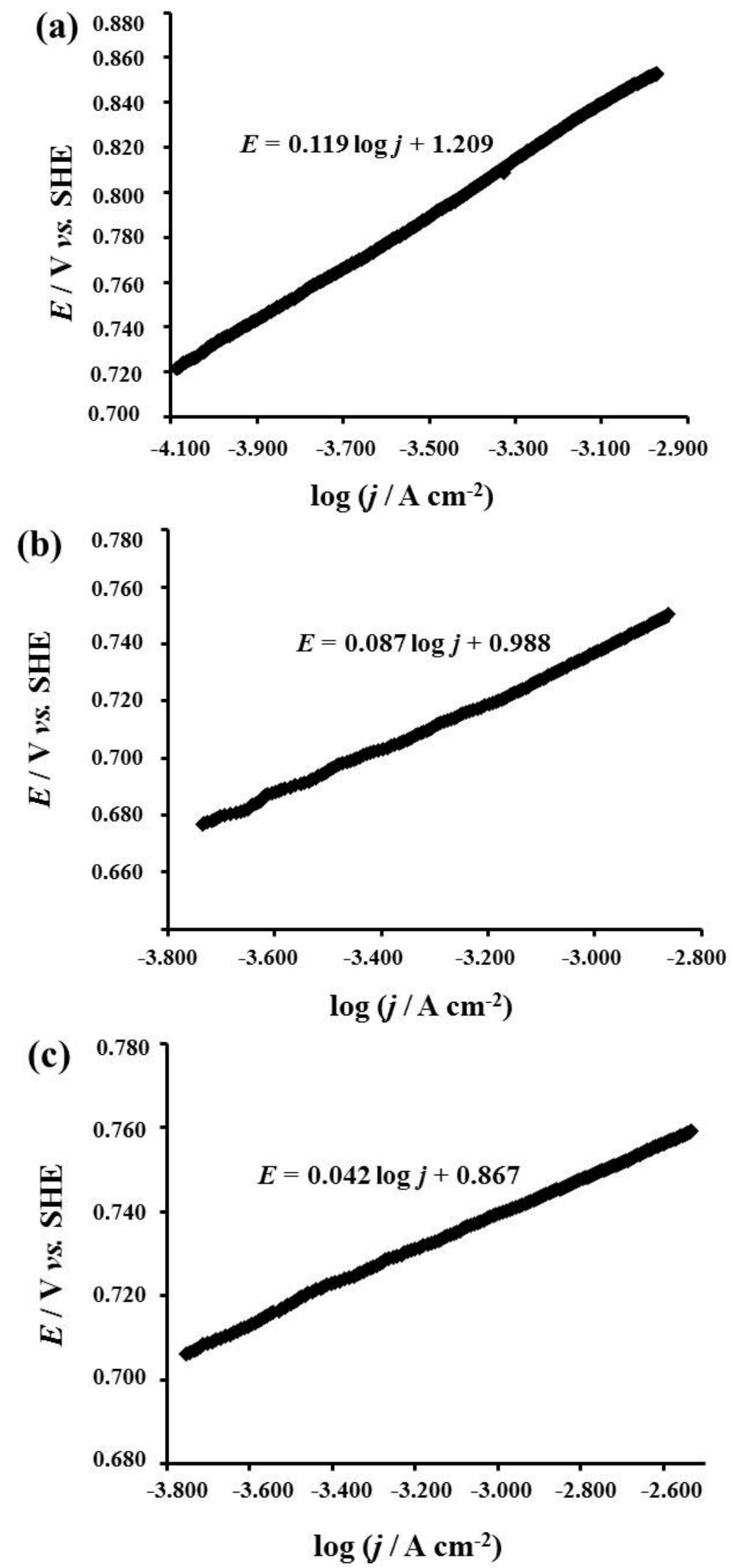

Figure 5. Tafel line of Pt (a), ${ }_{50} \mathrm{Pt}_{-50} \mathrm{RuO}_{2}(\boldsymbol{b})$ and ${ }_{50} \mathrm{Pt}_{50} \mathrm{OrO} \mathrm{r}_{2}(\mathrm{c})$ in $\mathrm{KOH} 0.5 \mathrm{M} ; \mathrm{v}=1 \mathrm{mV} \mathrm{s}{ }^{-1}$; $C E$ : platinum, $\mathrm{T}=25^{\circ} \mathrm{C}$

Oxygen evolution reaction is known to be a complex reaction. It depends normally on many factors such as electrode materials, experimental condition, and electrode preparation conditions. 
The following oxygen evolution reaction mechanism that has received much agreement among researchers in alkaline electrolytes is proposed as followed [22-24].

$$
\begin{aligned}
& \mathrm{S}+\mathrm{OH}^{-} \rightarrow \mathrm{SOH}+\mathrm{e}^{-} \\
& \mathrm{SOH}+\mathrm{OH}^{-} \rightarrow \mathrm{SO}^{-}+\mathrm{H}_{2} \mathrm{O} \\
& \mathrm{SO}^{-} \rightarrow \mathrm{SO}+\mathrm{e}^{-} \\
& 2 \mathrm{SO} \rightarrow 2 \mathrm{~S}+\mathrm{O}_{2}
\end{aligned}
$$

$\mathrm{S}$ represents the electrode active sites; $\mathrm{OH}, \mathrm{O}^{-}$and $\mathrm{O}$ represent the adsorbed intermediates.

Assuming step (15) of that mechanism as the rate determining step, the Tafel slope determined theoretically was about $120 \mathrm{mV} \mathrm{dec}^{-1}$. In the case that the rate determining step is supposed to be step (16), the Tafel slope would be $60 \mathrm{mV} \mathrm{dec}{ }^{-1}$. Tafel slopes are $40 \mathrm{mV} \mathrm{dec}^{-1}$ and $15 \mathrm{mV} \mathrm{dec}^{-1}$ in alkaline electrolyte if steps (17) and (18) were considered as rate determining steps respectively. Considering the platinum electrode with a Tafel slope of $119 \mathrm{mV} \mathrm{dec}^{-1}$, the rate determining step in the oxygen evolution process on this electrode is step (15). With ${ }_{50} \mathrm{Pt}_{-50} \mathrm{IrO}_{2}$ the Tafel slope is about $42 \mathrm{mV} \mathrm{dec}{ }^{-1}$ which is close to $40 \mathrm{mV} \mathrm{dec}{ }^{-1}$. Thus, on this electrode, step (17) could be the rate determining step in the oxygen evolution reaction. For the ${ }_{50} \mathrm{Pt}-{ }_{50} \mathrm{RuO}_{2}$ electrode, the Tafel slope is $87 \mathrm{mV} \mathrm{dec}{ }^{-1}$. As has been observed in acidic medium, that value is almost close to $120 \mathrm{mV} \mathrm{dec}^{-1}$ indicating that platinum effect seems to dominate the totally surface effect. Step (15) could be the rate determining step in the OER process.

\section{Conclusion}

The micrographs of ${ }_{50} \mathrm{Pt}-{ }_{50} \mathrm{RuO}_{2}$ and ${ }_{50} \mathrm{Pt}-{ }_{50} \mathrm{IrO}_{2}$ have revealed that their surfaces are rough with cracked structures. That of platinum was smooth, compact and homogeneous. The richer the electrode surface in platinum, thinner is the crack size and also more compact is the electrode surface.

Cyclic voltammetry investigations have revealed the presence of both $\mathrm{IrO}_{2}$ or $\mathrm{RuO}_{2}$ and $\mathrm{Pt}$ on the thermally prepared ${ }_{50} \mathrm{Pt}-{ }_{50} \mathrm{RuO}_{2}$ and ${ }_{50} \mathrm{Pt}-{ }_{50} \mathrm{IrO}_{2}$ electrode surface. The addition of metallic dioxide to platinum leads to electrodes with higher electrocatalytic activity than platinum towards oxygen evolution used as probe reaction. That electrocatalytic enhancement is due to a synergetic effect of the surface component. All the prepared electrodes showed different rate determining steps. Tafel slopes are found to be almost the same in acid and in alkaline electrolytes indicating the same rate determining steps for each electrode.

Acknowledgements: We greatly thank the Swiss National Funds for its financial support that allowed this work to be carried out. Our Team has received part of the grant IZ01Z0_146919 for that work. We also thank Prof. Cesar Pulgarin at the Swiss Federal Institute of Lausanne (Switzerland) and Prof. Ricardo Torres at the University of Antioquia (Colombia) for their help in that work.

\section{References}

[1] G. B. Tissot, A. Anglada, P. Dimitriou-Christidis, L. Rossi, J. S. Arey, C. Comninellis, Electrochemistry Communications 23 (2012) 48-51.

[2] X. D. Xiang, Q. M. Huang, Z. Fu, Y. L. Lin, W. Wu, S. J. Hu, W. S. Li, International Journal of Hydrogen Energy 37(5) (2012) 4710-4716. 
[3] C. C. Huang, Q. Wang, D.B. Xiang, H.B. Shao, Chinese Chemical Letters 22(12) (2011) 14811484.

[4] D. Basu, S. Basu, Electrochimica Acta, 56 (2011) 6106-6113.

[5] S. Ferro, D. Rosestolato, C. A. Martinez-Huitle, A. De Battisti, Electrochimica Acta 146 (2014) 257-261.

[6] Y. Chieng, C. Xu, L. Jia, J.D. Gale, L. Zhang, P.K. Shen, S.P. Jiang, Applied Catalysis B : Environmental 163 (2015) 96-104.

[7] Z. Y. Li, S. T. Shi, Q. S. Zhong, C. J. Zhang, C. W. Xu, Electrochimica Acta 146 (2014) 119-124.

[8] E. I. Papaioannou, A. Siokou, C. Comninellis, A. Katsaounis, Electrocatalysis, 4 (4) (2013) 375-381.

[9] L. Ouattara, A. L. G. Pohan, Revue Ivoirienne des Sciences et Technologie 17 (2011) 1-15

[10] B. Kouakou, L. Ouattara, A. Trokourey, Y. Bokra, Journal of Applied Sciences and Environmental Management 12 (4) (2008) 103-110.

[11] K. H. Kondro, L. Ouattara, A. Trokourey, Y. Bokra, Bulletin of the Chemical Society of Ethiopia 22(1) (2008) 125-134.

[12] A. Kapalka, G. Fóti, C. Comninellis, Electrochemistry Communications 10 (2008) 607-610.

[13] G. Rocchini, Corrosion Science, 34(12) (1993) 2019-2030

[14] L. A. De Faria, J. F. C. Boodts, S. Trasatti, Journal of Applied Electrochemistry 26(11) (1996) 1195-1199.

[15] N. Krstajic, S. Trasatti, Journal of Applied Electrochemistry 28(12) (1998) 1291-1297.

[16] L. Ouattara, T. Diaco, I. Duo, M. Panizza, G. Foti, Ch. Comninellis, Journal of the Electrochemical Society 150 (2) (2003) D41-D45.

[17] F. Moradi, C. Dehghanian, Progress in Natural Science: Materials International 24 (2) (2014) 134-141.

[18] D. J. Walton, L. D. Burke, M. M. Murphy, Electrochimica Acta 41(17) (1996) 2747-2751.

[19] E. Tsuji, A. Imanishi, K. I. Fukui, Y. Nakato, Electrochimica Acta 56 (2011) 2009-2016.

[20] V. I. Birss, A. Damjanovic, P. G. Hudson, Journal of Electrochemical Society 133(8) (1986) 1621-1625.

[21] G. Lodi, E. Sivieri, A. De Battisti, S. Trasatti, Journal of Applied Electrochemistry 8(2) (1978) 135-143

[22] C. Eun-Ok, K. Young-Uk, M. Sun-II, Bull. Korean Chemical Society 18 (9) (1997) 972-976

[23] C. Iwakura; K. Fukuda, H. Tamura, Electrochimica Acta 21 (1976) 501-508

[24] I. M. Sadiek, A. M. Mohammad, M. E. El-Shakre, M. S. El-Deab, International Journal of Hydrogen Energy 37(1) (2012) 68-77

(C) 2015 by the authors; licensee IAPC, Zagreb, Croatia. This article is an open-access article distributed under the terms and conditions of the Creative Commons Attribution license (http://creativecommons.org/licenses/by/4.0/) (cc) EY 